\title{
Breast Cancer Treatment: A Double-Edged Sword
}

\author{
Ishveen Chopra* and Avijeet S Chopra \\ Manticore Consulting Group LLC, Scottsdale, USA
}

Submission: February 23, 2018; Published: July 11, 2018

${ }^{*}$ Corresponding author: Ishveen Chopra, 14362 N. Frank Lloyd Wright Blvd., Ste. 100Scottsdale, AZ 85260, USA, Tel: 412-427-5627;

Email: ichopra@manticore.consulting

\begin{abstract}
With improvement in breast cancer detection and treatment, patient survival has improved, yet cardiotoxicity of the treatments is of significant concern. Breast cancer treatments may increase the risk of or worsen pre-existing heart disease. Management of breast cancer treatment-related cardiotoxicity is very challenging due to a broad spectrum of clinical and subclinical events. Lack of consensus regarding follow-up, strategies for detection, monitoring, and management, and possible prioritization of cancer treatment may hinder optimal cardiovascular disease management. An interdisciplinary and integrated approach to cardiovascular management in the those diagnosed with incident cancer may help mitigate the risk of cardiotoxicity.
\end{abstract}

Keywords: Breast cancer; Cardiotoxicity; Cardioprotective agents; Cardiovascular Management; Cardio-oncology

\section{Opinion}

Breast cancer is the second most common form of cancer among women in the United States [1]. Although current breast cancer treatments have improved survival, cardiotoxicity of the treatments is of significant concern. Breast cancer treatments, such as radiotherapy, chemotherapy, hormone therapy, and targeted therapy may increase the risk of or worsen pre-existing heart disease, resulting in major coronary events (e.g., heart attack) and even death [2-4]. Radiotherapy is of particular concern for breast cancer because of its cell damaging effects and proximity to the heart. Anthracyclines and trastuzumab typically result in clinical heart failure or heart attack. Risk of cardiotoxicity can be exacerbated by pre-existing cardiac disease, type II diabetes, very young or old age, and concurrent radiotherapy and chemotherapy [5-7].

Management of breast cancer treatment-related cardiotoxicity is very challenging. Breast cancer therapy-related cardiovascular disease may present a broad spectrum of clinical and subclinical events, such as left ventricular ejection fraction, symptomatic congestive heart failure, and cardiovascular-related deaths. Further, cardiotoxicity is clinically categorized into acute and chronic toxicity. Acute cardiotoxicity arises anytime from the initiation of therapy to several weeks after treatment termination. Chronic cardiotoxicity is characterized by clinical heart failure or subclinical decline in myocardial infarction within one year after termination of therapy. Chronic cardiomyopathy is not associated with timing of initiation and generally begins as asymptomatic diastolic or systolic dysfunction, which then progresses to heart failure [5-8].

Given the variability in clinical presentation of cardiotoxicity, routine management of cardiac health is crucial to alleviate cancer treatment-related cardiotoxicity. This is of even more vital concern in patients with pre-existing cardiac disease. Despite numerous guidelines and recommendation about management of cardiotoxicity, clinical approaches are variable and inconsistent because of the three reasons.8 First, there is no consensus about the timing of potentially cardiotoxic treatment and routine monitoring is not based on validated algorithms. Second, there is a lack of optimal strategies for detection, monitoring, and management of cancer therapy-associated cardiovascular disease.Third, cancer being the dominant condition, it "eclipses" the management of heart disease. Given the complicated relationship between heart disease and cancer, a multidisciplinary approach incorporating cardiology and oncology expertise is needed to optimize short-term and longterm patient care. Future clinical research on integrated clinical parameters, predictive biomarkers with imaging techniques could provide insight into drug-related toxicity assessment and tailored strategies to improve breast cancer patients' management.

Besides timely detection and monitoring, the cardioprotective agents can mitigate the risk of cardiotoxicity, especially in high risk populations. Cardioprotective agents include antihypertensives, 
statins, and aspirin. A meta-analysis of randomized clinical trials and observational studies in general population indicated that statins, $\beta$-blockers, and angiotensin-converting enzyme inhibitors (ACEi) or angiotensin II receptor blockers (ARB) can reduce cancer treatment-related cardiotoxicity. Cardiac events were significantly reduced with $\beta$-blockers (relative risk, $\mathrm{RR}=$ 0.31 [95\% CI 0.16-0.63], $\mathrm{P}=0.001)$, statins $(\mathrm{RR}=0.31$ [95\% CI 0.13-0.77], $\mathrm{P}=0.01$ ) and ACEi/ARB (RR=0.11 [95\% CI 0.04-0.29], $\mathrm{P}<0.0001$ ) [9]. These medications are central to preventing congestive heart failure, stable angina, post-acute myocardial infarction, and any further complications after initial event or revascularization.

Since both heart disease and cancer are considered lifethreatening conditions, it may be very challenging for clinicians to implement interventions to manage both conditions simultaneously. In this context, the recent healthcare delivery models, such as the medical home may help in overcoming the challenges to coordination across different providers, thereby improving management of multiple chronic conditions [10]. Therefore, an interdisciplinary and integrated approach to cardiovascular management in the those diagnosed with incident cancer, such as the burgeoning cardio-oncology clinics, would improve cardiovascular outcomes [11].

\section{References}

1. (2016) Cancer facts \& figures. American Cancer Society.
2. Yusuf SW, Razeghi P, Yeh ET (2008) The diagnosis and management of cardiovascular disease in cancer patients. Curr Probl Cardiol 33(4): 163-196.

3. Herrmann J, Lerman A, Sandhu NP, Villarraga HR, Mulvagh SL, et al. (2014) Evaluation and management of patients with heart disease and cancer: cardio-oncology. Mayo Clin Proc 89(9): 1287-1306.

4. Accordino MK, Neugut AI, Hershman DL (2014) Cardiac effects of anticancer therapy in the elderly. JClinOncol32(24):2654-2661.

5. Marks LB, ConstineLS, AdamsMJ (2015) Cardiotoxicity of radiation therapy for malignancy.

6. FloydJ,Morgan, JP, BergS (2015) Cardiotoxicity of anthracycline-like chemotherapy agents.

7. MorganJP (2015) Cardiotoxicity of trastazumab and other HER2targeted agents.

8. Hahn VS, Lenihan DJ, Ky B (2014) Cancer therapy-induced cardiotoxicity: basic mechanisms and potential cardioprotective therapies. J Am Heart Assoc 3(2): e000665.

9. Kalam K, Marwick TH (2013) Role of cardioprotective therapy for prevention of cardiotoxicity with chemotherapy: a systematic review and meta-analysis. Eur J Cancer 49(13): 2900-2909.

10. Beadles CA, Farley JF, Ellis AR, Lichstein JC, Morrissey JP, et al. (2015) Do medical homes increase medication adherence for persons with multiple chronic conditions? MedCare 53(2): 168-176.

11. http://www.mayoclinic.org/medical-professionals/clinical-updates/ cardiovascular/cardio-oncology-clinics-integrate-specialty-clinicalcare

\section{Your next submission with Juniper Publishers will reach you the below assets}

- Quality Editorial service

- Swift Peer Review

- Reprints availability

- E-prints Service

- Manuscript Podcast for convenient understanding

- Global attainment for your research

- Manuscript accessibility in different formats

( Pdf, E-pub, Full Text, Audio)

- Unceasing customer service

Track the below URL for one-step submission https://juniperpublishers.com/online-submission.php 